\title{
Synthesis of Poly(butylene succinate) and Poly(ethylene succinate) Including Diglycollate Moiety
}

\author{
Akihiro OISHI, Min Zhang, Kazuo NaKayama, Takashi MasudA, and Yoichi TAguCHI ${ }^{\dagger}$ \\ National Institute of Advanced Industrial Science and Technology (AIST), \\ Central 5, 1-1-1, Higashi, Tsukuba 305-8565, Japan
}

(Received January 10, 2006; Accepted March 14, 2006; Published June 9, 2006)

\begin{abstract}
Poly(butylene succinate) (PBS) copolymers were prepared from succinic acid, diglycollic acid, and 1,4-butanediol, in the presence of titanium tetraisopropoxide and magnesium hydrogen phosphate trihydrate. All the polymers produced exhibited a higher number-average molecular weight than 65,000 . The composition of the copolymers was found to be almost the same as the feed composition. The copolymers exhibited a higher break strain compared to the homopolymer. The biodegradability of copolymers showed a maximum when $2 \%$ diglycollic acid was added. However, the addition of more diglycollic acid decreased biodegradability. Poly(ethylene succinate) (PES) copolymers, including diglycollate moiety, were also prepared from succinic acid, diglycollic acid, and ethylene glycol, using the same reaction conditions as the PBS copolymers. Unlike the PBS copolymers, the molecular weights of the PES copolymers decreased for an increasing amount of diglycollate while the biodegradability rose with an increase of the diglycollate ratio in the copolymers, in the range 0-20\%. [doi:10.1295/polymj.PJ2005206]

KEY WORDS Poly(butylene succinate) / Poly(ethylene succinate) / Diglycollic Acid / Copolymerization / Break Strain / Biodegradation /
\end{abstract}

Much attention has been paid to biodegradable polymers for the production of environmentally friendly plastics. Such plastics would eventually decompose into carbon dioxide and water in nature. It is well known aliphatic polyesters are good biodegradable polymers and exhibit many excellent properties. ${ }^{1-4}$ Poly(butylene succinate) (PBS), an aliphatic polyester, exhibits good thermal and mechanical properties similar to polyethylene and polypropylene. The improvement of the PBS properties has been widely investigated by many scientists. ${ }^{5-7}$

Recently, we reported the preparation of various PBS copolymers from succinic acid, 1,4-butanediol and various additional compounds, such as $\varepsilon$-caprolactone, ${ }^{7}$ monoacylglycerol, ${ }^{8}$ 3-alkoky-1,2-propanediol $^{9}$ and cyclohexane dimethanol. ${ }^{10}$ The copolymer including $5 \mathrm{~mol} \%$ 3-octadecyloxy-1,2-propanediol exhibited a high break strain of $833 \%$, whereas the biodegradation rate of the copolymer was slower than the homopolymer. ${ }^{9}$

In this report, PBS copolymers, including diglycollic acid, were synthesized and their properties were studied. Although diglycollic acid (2) has a similar structure to succinic acid (1), it possesses ether-oxygen in molecules and thus, thermal, mechanical and biodegradable properties are expected to be different. The synthesis of poly(ethylene succinate) (PES), including diglycollic acid, and its properties were also studied.

\section{EXPERIMENTAL}

\section{Materials}

Succinic acid (1), 1,4-butanediol (3), titanium tetraisopropoxide, magnesium hydrogen phosphate trihydrate and diglycollic acid (Wako Pure Chemical) were used without further purification. Commercial compost soil (Tokawa Heiwa Noen) was purchased for the biodegradation test.

\section{Tensile Test}

Films (about $0.2 \mathrm{~mm}$ thick) were prepared using the heat-press method at $200 \mathrm{~kg} \mathrm{~cm}^{-2}, 140^{\circ} \mathrm{C}$. All tensile measurements were performed using a TOYO BALDWIN SS-207-EP tester at room temperature. Experiments were performed at a constant crosshead speed of $10 \mathrm{~mm} / \mathrm{min}$. At least three samples were tested under the same conditions for each polymer. The average value was estimated.

\section{Degradation of Polymers}

Films of initial dimension $25 \times 25 \times 0.2 \mathrm{~mm}$ were placed in compost soil at $30^{\circ} \mathrm{C}$ and $95 \%$ moisture. The films were removed at regular intervals, washed with distilled water and dried to constant weight in vacuum before analysis. For each test, three films were used and the average value of their weight-loss amounts was taken as the final result.

${ }^{\dagger}$ To whom correspondence should be addressed (Tel: +81-29-861-4576, Fax: +81-29-861-4576, E-mail: y-taguchi@aist.go.jp). 
Synthesis of PBS and PES Including Diglycollate Moiety

Table I. $M_{\mathrm{n}}$ and $M_{\mathrm{w}} / M_{\mathrm{n}}$ of PBS copolymers including diglycollic acid (1) ${ }^{\mathrm{a}}$

\begin{tabular}{ccccclcc}
\hline Run & $\begin{array}{c}1 \\
\mathrm{mmol}\end{array}$ & $\begin{array}{c}2 \\
\mathrm{mmol}\end{array}$ & $\begin{array}{c}3 \\
\mathrm{mmol}\end{array}$ & $1 / 2^{\mathrm{b}}$ & Product & $M_{\mathrm{n}} \mathrm{c}^{\mathrm{c}}$ & $M_{\mathrm{w}} / M_{\mathrm{n}}{ }^{\mathrm{c}}$ \\
\hline 1 & 180 & 0 & 198 & $100 / 0$ & PBS & 86,300 & 1.97 \\
2 & 178 & 2 & 198 & $99 / 1$ & PBSDG1 & 89,600 & 2.06 \\
3 & 176 & 4 & 198 & $98 / 2$ & PBSDG2 & 84,500 & 2.08 \\
4 & 171 & 9 & 198 & $95 / 5$ & PBSDG5 & 80,100 & 2.19 \\
5 & 162 & 18 & 198 & $90 / 10$ & PBSDG10 & 75,600 & 2.09 \\
6 & 144 & 45 & 198 & $80 / 20$ & PBSDG20 & 79,200 & 2.05 \\
7 & 90 & 90 & 198 & $50 / 50$ & PBSDG50 & 67,900 & 2.02 \\
8 & 36 & 144 & 198 & $20 / 80$ & PBSDG80 & 65,400 & 1.96 \\
9 & 0 & 180 & 198 & $0 / 100$ & PBDG & 79,600 & 1.96 \\
\hline
\end{tabular}

${ }^{\mathrm{a}} \mathrm{Ti}(\mathrm{O}-\mathrm{i}-\mathrm{Pr})_{4} 0.116 \mathrm{mmol}, \mathrm{MgPO}_{4} \cdot 3 \mathrm{H}_{2} \mathrm{O} 0.04 \mathrm{mmol}, 230^{\circ} \mathrm{C}$, reaction time $1-1.5 \mathrm{~h} .{ }^{\mathrm{b}} \mathrm{Molar}$ ratio. ${ }^{\mathrm{c}}$ Determined by GPC.

\section{Preparation of Copolymers}

The typical procedure was as follows: a fournecked $100 \mathrm{~mL}$ flask was charged with $20.18 \mathrm{~g}$ (171 mmol) succinic acid, $17.82 \mathrm{~g}$ (198 mmol) 1,4-butanediol, $1.21 \mathrm{~g}(9.0 \mathrm{mmol})$ diglycollic acid, $0.030 \mathrm{~g}(0.12$ mmol) titanium tetraisopropoxide and $0.0069 \mathrm{~g}(0.04$ mmol) magnesium hydrogen phosphate trihydrate under dry $\mathrm{N}_{2}$ atmosphere. The flask, with a gas introduction inlet and outlet, connected to a condenser was first immersed in a silicon oil bath preset at $230^{\circ} \mathrm{C}$, then heated, to remove the esterification reaction byproduct of water, for $1 \mathrm{~h}$. Subsequently, the condenser was removed and polycondensation was carried out, over a gradually decreasing pressure, for a final vacu- um of less than $0.1 \mathrm{mmHg}$. Polycondensation was concluded once the viscosity of the product reached high enough to twist around stirring rod.

\section{RESULTS AND DISCUSSION}

The synthesis of PBS copolymers, including diglycollate moiety, was carried out from succinic acid (1), diglycollic acid (2), and 1,4-butanediol (3), using titanium tetraisopropoxide as the catalyst. Furthermore, magnesium hydrogen phosphate was also used in the reaction as a co-catalyst because it has an acceleration effect in the synthesis of PBS. ${ }^{11}$

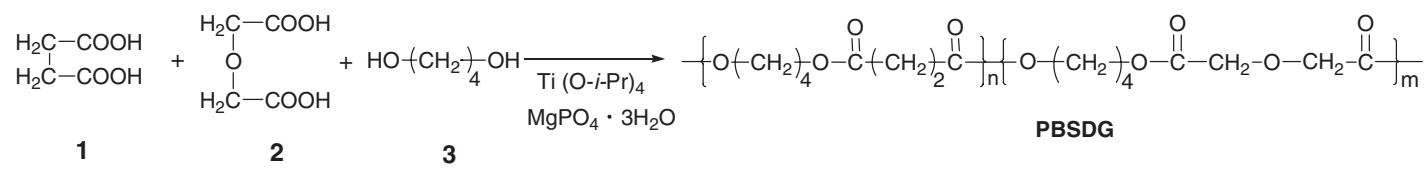

Table I shows number-average molecular weights $\left(M_{\mathrm{n}}\right)$ and the molecular weight distribution $\left(M_{\mathrm{w}} / M_{\mathrm{n}}\right)$ of obtained polymers. An $M_{\mathrm{n}}$ higher than 65,000 was obtained for all polymers. The $M_{\mathrm{w}} / M_{\mathrm{n}}$ ratio of the polymers was found to be between 1.96 and 2.19.

Figure 1 is the ${ }^{1} \mathrm{H}$ NMR spectrum of PBSDG50: the compositions of 1 and 2 in the copolymers were estimated from the ratio of the methylene proton resonance intensities of $\mathrm{Hb}$ or $\mathrm{Hc}$, and $\mathrm{Hd}$ or $\mathrm{He}$, with respect to the intensity of Ha. The results of the estimate are given in Table II. The compositions of the 1 and 2 moieties in the copolymers were almost the same as the feed compositions of 1 and 2.

In Table III the thermal properties of the copolymers are presented: the glass transition temperature $\left(T_{\mathrm{g}}\right)$ increases and the melting temperature $\left(T_{\mathrm{m}}\right)$ decreases with an increase of 2 in the copolymers. These trends are as expected with the PBS copolymers containing monoacylglycerol ${ }^{8}$ and 3-alkoky-1,2-propanediol. $^{9}$
In Table IV the tensile tests of the produced polymers are presented: the values of elastic modulus, yield stress, and break stress decrease as the ratio of 2 in the copolymers increases and become negligible at PBSDG50 and PBSDG80. PBS copolymers containing 3-alkoxy-1,2-propanediol exhibit a higher break strain than the PBS homopolymer. ${ }^{9}$ Copolymers in Table IV also exhibit a higher break strain than $\mathrm{PBS}$ and PBDG.

In Figure 2 the biodegradation experimental results of PBS, PBSDG2, PBSDG5, PBSDG10, PBSDG20, PBSDG50, and PBDG, in commercial compost soil under $30^{\circ} \mathrm{C}$ and $95 \% \mathrm{RH}$, are presented. The weight loss of PBS by hydrolysis in air under the same conditions was scarcely detected in 8 weeks. Biodegradability was thus expressed as the weight loss, as a function of buried time, for $25 \times 25 \times 0.2 \mathrm{~mm}$ films. PBSDG2 achieved the maximum biodegradability. However, the biodegradability decreases as the ratio of 2 in the copolymers increases. PBDG, a polymer 


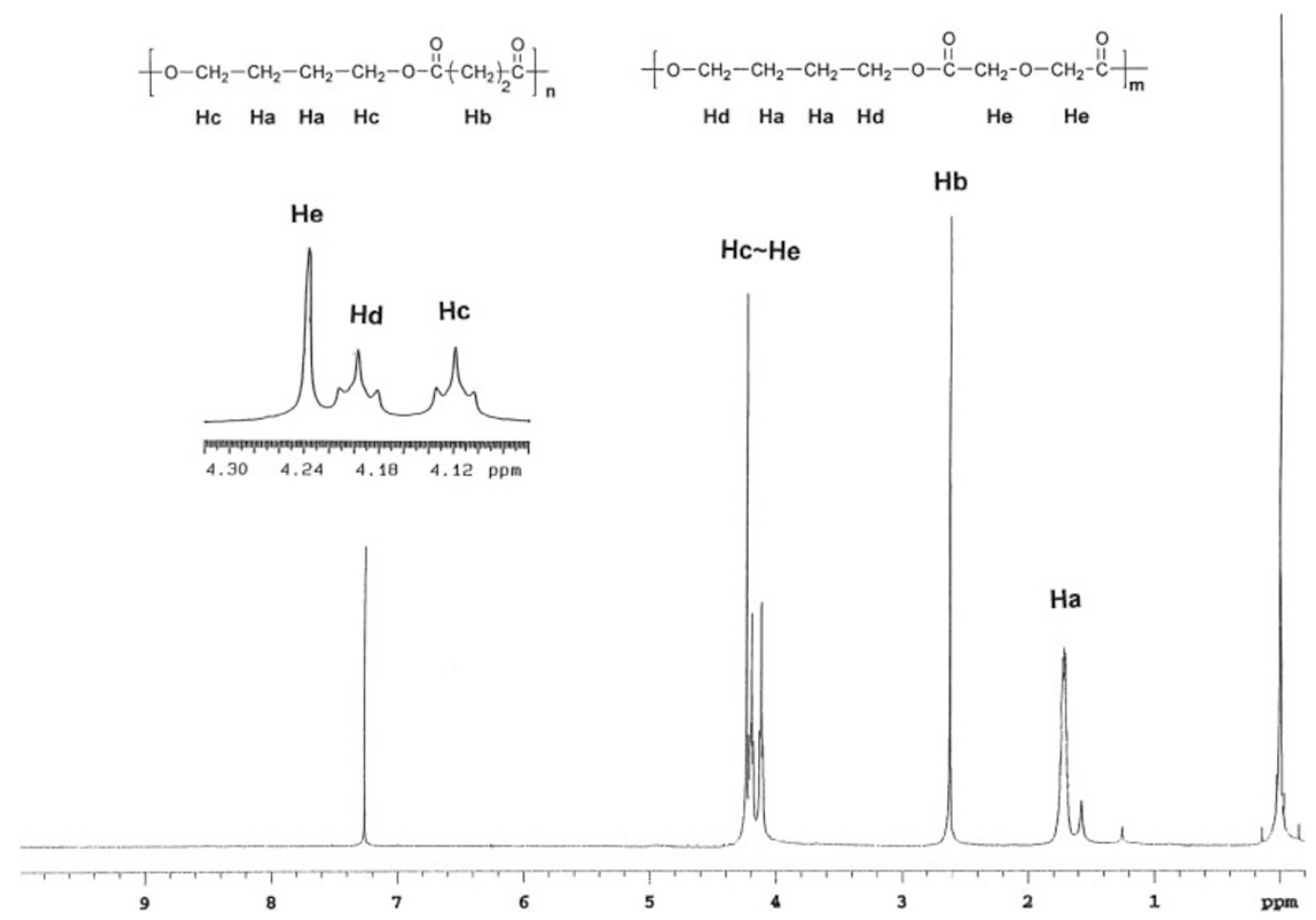

Figure 1. ${ }^{1} \mathrm{H}$ NMR spectrum of PBSDG50.

Table II. The ratio of components of succinate and diglycollate in copolymers by NMR analysis

\begin{tabular}{|c|c|c|c|c|c|}
\hline & \multirow{2}{*}{$\begin{array}{c}\text { Monomer } \\
1 / 2\end{array}$} & \multicolumn{2}{|c|}{$\begin{array}{c}\text { The ratio of } \\
\text { succinate }(\%)\end{array}$} & \multicolumn{2}{|c|}{$\begin{array}{c}\text { The ratio of } \\
\text { diglycollate }(\%)\end{array}$} \\
\hline & & $\mathrm{Hb} / \mathrm{Ha}$ & $\mathrm{Hc} / \mathrm{Ha}$ & $\mathrm{Hd} / \mathrm{Ha}$ & $\mathrm{He} / \mathrm{Ha}$ \\
\hline PBS & $100 / 0$ & 101 & 99 & 0 & 0 \\
\hline PBSD1 & $99 / 1$ & 99 & 99 & 1 & 3 \\
\hline PBSDG2 & $98 / 2$ & 99 & 98 & 1 & 5 \\
\hline PBSDG5 & $95 / 5$ & 96 & 95 & 5 & 5 \\
\hline PBSDG10 & $90 / 10$ & 90 & 90 & 10 & 9 \\
\hline PBSDG20 & $80 / 20$ & 78 & 79 & 20 & 19 \\
\hline PBSDG50 & $50 / 50$ & 46 & 51 & 47 & 48 \\
\hline PBSDG80 & $20 / 80$ & 18 & 21 & 75 & 82 \\
\hline PBDG & $0 / 100$ & 0 & 0 & 95 & 98 \\
\hline
\end{tabular}

Table III. Thermal properties of PBS copolymers including diglicollic acid

\begin{tabular}{lcccc}
\hline Product & $\begin{array}{c}T_{\mathrm{g}} \\
{ }^{\circ} \mathrm{C}\end{array}$ & $\begin{array}{c}T_{\mathrm{m}} \\
{ }^{\circ} \mathrm{C}\end{array}$ & $\begin{array}{c}\Delta H_{\mathrm{m}} \\
\mathrm{mJ} / \mathrm{mg}\end{array}$ & $\begin{array}{c}\mathrm{Td} 2 \\
{ }^{\circ} \mathrm{C}\end{array}$ \\
\hline PBS & -35.7 & 112 & 128 & 304 \\
PBSD1 & -34.3 & 114 & 105 & 311 \\
PBSDG2 & -33.9 & 114 & 110 & 312 \\
PBSDG5 & -34.6 & 111 & 112 & 318 \\
PBSDG10 & -31.9 & 106 & 94 & 312 \\
PBSDG20 & -37.5 & 95 & 97 & 309 \\
PBSDG50 & -35.0 & 55 & 43 & 318 \\
PBSDG80 & -29.9 & 47 & 57 & 326 \\
PBDG & -27.2 & 59 & 68 & 321 \\
\hline
\end{tabular}

Table IV. Mechanical properties of PBS copolymers including diglycollic acid

\begin{tabular}{lrccc}
\hline Product & $\begin{array}{c}\text { Elastic } \\
\text { MPa }\end{array}$ & $\begin{array}{c}\text { Yield Stress } \\
\text { MPa }\end{array}$ & $\begin{array}{c}\text { Break Stress } \\
\text { MPa }\end{array}$ & $\begin{array}{c}\text { Break Strain } \\
\%\end{array}$ \\
\hline PBS & 301.0 & 29.3 & 29.3 & 210.3 \\
PBSD1 & 268.8 & 29.4 & 48.7 & 589.2 \\
PBSDG2 & 274.3 & 27.1 & 30.8 & 292.5 \\
PBSDG5 & 268.4 & 24.7 & 45.2 & 604.9 \\
PBSDG10 & 231.3 & 21.8 & 26.8 & 360.4 \\
PBSDG20 & 178.7 & 17.2 & 32.1 & 610.2 \\
PBSDG50 & 1.8 & 6.4 & 19.1 & 921.0 \\
PBSDG80 & 2.2 & 6.2 & 15.5 & 542.4 \\
PBDG & 86.7 & 13.0 & 31.7 & 512.8 \\
\hline
\end{tabular}

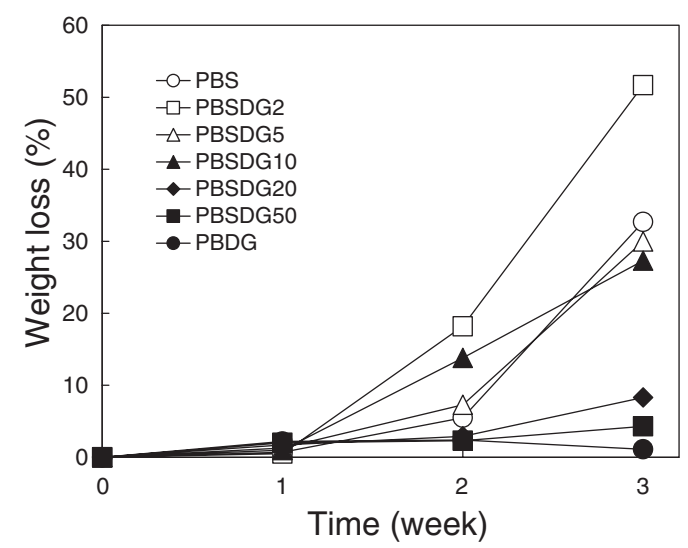

Figure 2. Buried time dependence of biodegradation of PBS copolymers. 
Synthesis of PBS and PES Including Diglycollate Moiety

Table V. $M_{\mathrm{n}}$ and $M_{\mathrm{w}} / M_{\mathrm{n}}$ of PES copolymers including diglycollic acid ${ }^{\mathrm{a}}$

\begin{tabular}{ccccclcc}
\hline Run & $\begin{array}{c}1 \\
\mathrm{mmol}\end{array}$ & $\begin{array}{c}2 \\
\mathrm{mmol}\end{array}$ & $\begin{array}{c}3 \\
\mathrm{mmol}\end{array}$ & $1 / 2^{\mathrm{b}}$ & Product & $M_{\mathrm{n}}{ }^{\mathrm{c}}$ & $M_{\mathrm{w}} / M_{\mathrm{n}}{ }^{\mathrm{c}}$ \\
\hline 1 & 180 & 0 & 198 & $100 / 0$ & PES & 72,300 & 2.09 \\
2 & 178 & 2 & 198 & $99 / 1$ & PESDG1 & 76,900 & 2.20 \\
3 & 176 & 4 & 198 & $98 / 2$ & PESDG2 & 79,800 & 1.99 \\
4 & 171 & 9 & 198 & $95 / 5$ & PESDG5 & 72,700 & 2.08 \\
5 & 162 & 18 & 198 & $90 / 10$ & PESDG10 & 65,300 & 2.16 \\
6 & 144 & 45 & 198 & $80 / 20$ & PESDG20 & 52,700 & 1.83 \\
7 & 90 & 90 & 198 & $50 / 50$ & PESDG50 & 42,800 & 2.79 \\
8 & 36 & 144 & 198 & $20 / 80$ & PESDG80 & 37,400 & 3.18 \\
9 & 0 & 180 & 198 & $0 / 100$ & PEDG & 30,500 & 2.17 \\
\hline
\end{tabular}

${ }^{\mathrm{a}} \mathrm{Ti}(\mathrm{O}-i-\mathrm{Pr})_{4} 0.116 \mathrm{mmol}, \mathrm{MgPO}_{4} \cdot 3 \mathrm{H}_{2} \mathrm{O} 0.04 \mathrm{mmol}, 230^{\circ} \mathrm{C}$, reaction time $1-1.5 \mathrm{~h} .{ }^{\mathrm{b}} \mathrm{Molar}$ ratio. ${ }^{\mathrm{c}}$ Determined by GPC.

obtained from 2 and 3, exhibits no biodegradability under our test conditions.

The synthesis of poly(ethylene succinate) (PES) copolymers, including diglycollate moiety, was also studied. PES and its copolymers have also been reported to be biodegradable. ${ }^{12,13}$ Although the synthesis of PES, via ring-opening polymerization of succin- ic anhydride and ethylene oxide ${ }^{12,14}$ or by polycondensation of dimethyl succinate and ethylene glycol, ${ }^{15}$ has been reported, the molecular weights were not high enough. In our experiment PES with a high molecular weight was synthesized using the same polycondensation as in the synthesis of the PBS copolymers.

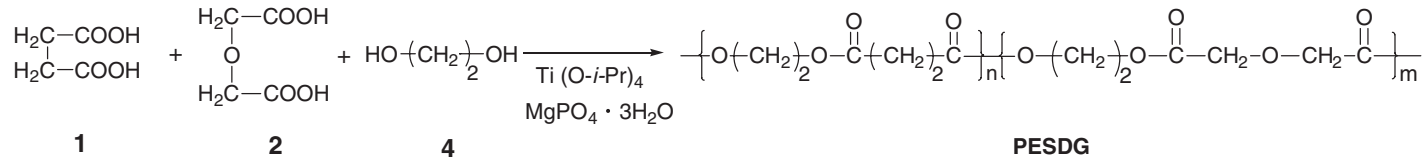

In Table $\mathrm{V}$ the number-average molecular weights $\left(M_{\mathrm{n}}\right)$ and the molecular weight distribution $\left(M_{\mathrm{w}} / M_{\mathrm{n}}\right)$ of PES copolymers are presented. Copolymers with an $M_{\mathrm{n}}$ higher than 60,000 could be obtained at 0 $10 \mathrm{~mol} \%$ of 2. Unlike PBS copolymers, the $M_{\mathrm{n}}$ of the copolymers decreased with an increasing amount of 2. The $M_{\mathrm{n}}$ of PEDG, a polymer obtained from 2 and 4 , decreased to $30,500 . M_{\mathrm{w}} / M_{\mathrm{n}}$ of PESDG50 and PESDG80 was higher than others. The reason was presumed that a part of the copolymers depolymerized.

Figure 3 is the ${ }^{1} \mathrm{H}$ NMR spectrum of PESDG50: the composition of 1 and 2 in the copolymers were estimated from the ratio of the methylene proton resonance intensity of $\mathrm{Hb}$ with respect to the intensity of Ha. The results are presented in Table VI. The composition of 1 and 2 in all copolymers was almost the same as the feed composition of 1 and 2. This result is in agreement with the PBS copolymers (Table II).

In Table VII the thermal properties of the synthesized copolymers are presented. The melting temperature $\left(T_{\mathrm{m}}\right)$ was not measured using the DSC measurement of the copolymers that include more than 5\% of 2. The loss of the DSC peak can be attributed to the amorphousness of the copolymers. The same phenomenon is also observed for the poly(BS-co-ES) copolymers. ${ }^{13}$
In Table VIII the results of the tensile tests of the synthesized polymers are presented. PESDG10 and PESDG20 exhibit a higher break strain than the PES homopolymer. The results are agreement with the tendency of PBS copolymers (Table IV). However, data of PESDG50, PESDG80, and PEDG could not be measured because it was extremely difficult to prepare films. The reason was presumed because of their lower molecular weights and amorphousness.

In Figure 4 the experimental biodegradation results of PES, PESDG1, PESDG2, PESDG5, PESDG10, and PESDG20 are presented: the biodegradability rises as the ratio of 2 in the copolymers increases in the range of these compositions. The biodegradability of PES copolymers was much lower than that of the PBS copolymers in these experiments.

\section{CONCLUSION}

PBS copolymers with an $M_{\mathrm{n}}$ higher than 65,000 , including diglycollate, were obtained via the reactions of 1,2 , and 3 . The compositions of the copolymers were almost the same as the feed compositions. However, the values of the elastic modulus, yield stress and break stress decreased. The break strain increased with an increase of 2 . The biodegradability of copolymers peaks at a $2 \%$ diglycollate ratio, but decreases 


\section{A. OISHI et al.}

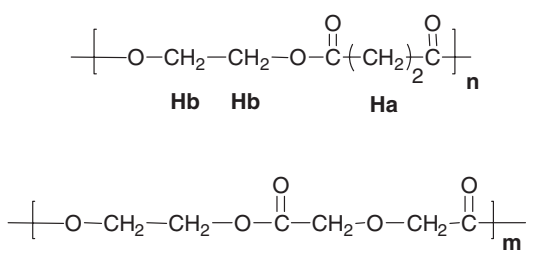

$\mathrm{Hb} \quad \mathrm{Hb} \quad \mathrm{Hb} \quad \mathrm{Hb}$

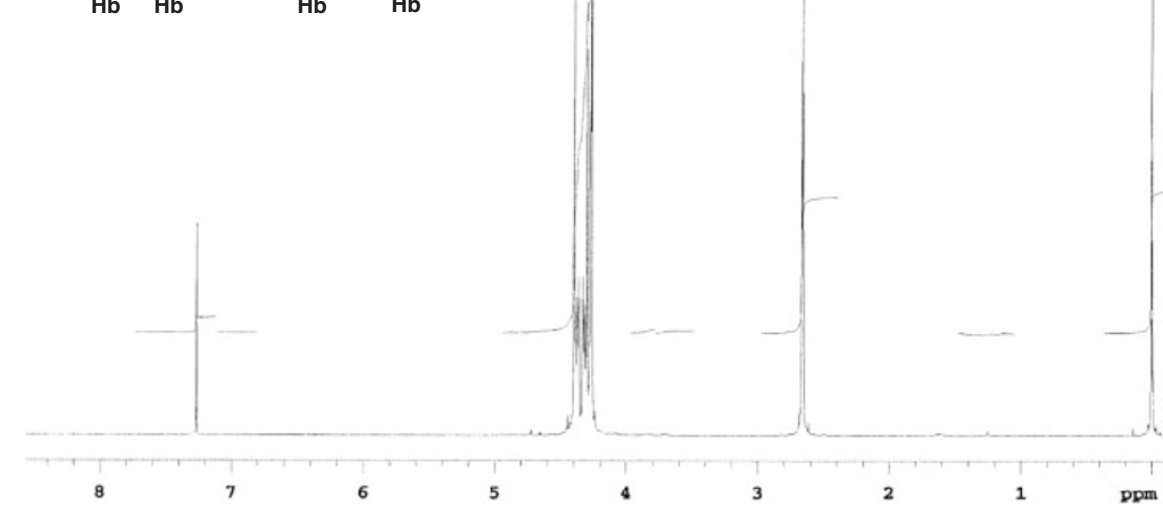

Figure 3. $\quad{ }^{1} \mathrm{H}$ NMR spectrum of PESDG50.

Table VI. The ratio of components of succinate and diglycollate by NMR analysis

\begin{tabular}{lccc}
\hline & Monomer & & The ratio of diglycollate $(\%)$ \\
\cline { 2 - 2 } & $1 / 2$ & & $(\mathrm{Ha}-\mathrm{Hb}) /(\mathrm{Ha}+\mathrm{Hb})$ \\
\hline PES & $100 / 0$ & 0 \\
PESDG1 & $99 / 1$ & 1.5 \\
PESDG2 & $98 / 2$ & 2.1 \\
PESDG5 & $95 / 5$ & 5.0 \\
PESDG10 & $90 / 10$ & 10.5 \\
PESDG20 & $80 / 20$ & 21.0 \\
PESDG50 & $50 / 50$ & 58.4 \\
PESDG80 & $20 / 80$ & 87.7 \\
PEDG & $0 / 100$ & 100 \\
\hline
\end{tabular}

Table VII. Thermal properties of PES copolymers including diglycollic acid

\begin{tabular}{lrccc}
\hline Product & $\begin{array}{r}T_{\mathrm{g}} \\
{ }^{\circ} \mathrm{C}\end{array}$ & $\begin{array}{c}T_{\mathrm{m}} \\
{ }^{\circ} \mathrm{C}\end{array}$ & $\begin{array}{c}\Delta H_{\mathrm{m}} \\
\mathrm{mJ} / \mathrm{mg}\end{array}$ & $\begin{array}{c}\mathrm{Td} 2 \\
{ }^{\circ} \mathrm{C}\end{array}$ \\
\hline PES & -10.6 & 99.6 & 88 & 299 \\
PESD1 & -10.5 & 98.0 & 78 & 295 \\
PESDG2 & -9.6 & 97.9 & 55 & 296 \\
PESDG5 & -10.3 & 92.0 & $\times$ & 311 \\
PESDG10 & -10.1 & $\times$ & $\times$ & 305 \\
PESDG20 & -8.5 & $\times$ & $\times$ & 300 \\
PESDG50 & -3.9 & $\times$ & $\times$ & 305 \\
PESDG80 & 1.2 & $\times$ & $\times$ & 305 \\
PEDG & 3.2 & $\times$ & $\times$ & 312 \\
\hline
\end{tabular}

Table VIII. Mechanical properties of PES copolymers including diglycollic acid

\begin{tabular}{lcccc}
\hline Product & $\begin{array}{c}\text { Elastic } \\
\text { MPa }\end{array}$ & $\begin{array}{c}\text { Yield Stress } \\
\text { MPa }\end{array}$ & $\begin{array}{c}\text { Break Stress } \\
\text { MPa }\end{array}$ & $\begin{array}{c}\text { Break Strain } \\
\%\end{array}$ \\
\hline PES & 383.6 & 23.8 & 33.8 & 439.0 \\
PESD1 & 351.0 & 22.2 & 44.6 & 676.0 \\
PESDG2 & 321.5 & 21.8 & 28.6 & 422.9 \\
PESDG5 & 235.4 & 20.4 & 38.7 & 716.0 \\
PESDG10 & 215.0 & 17.5 & 39.0 & 834.3 \\
PESDG20 & 109.5 & 11.7 & 21.5 & 859.2 \\
PESDG50 & $\times$ & $\times$ & $\times$ & $\times$ \\
PESDG80 & $\times$ & $\times$ & $\times$ & $\times$ \\
PEDG & $\times$ & $\times$ & $\times$ & $\times$ \\
\hline
\end{tabular}

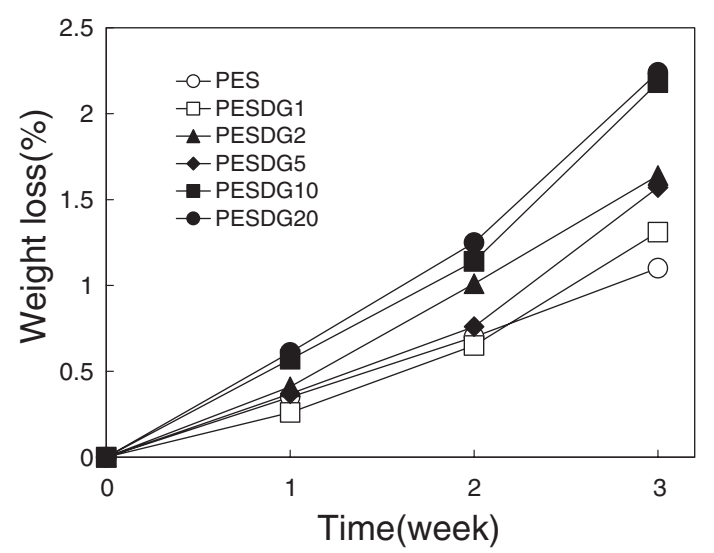

Figure 4. Buried time dependence of biodegradation of PES copolymers. 
with a further rise in the diglycollate ratio. This result suggests that there is the possibility of biodegradability control based on the amount of 2 .

PES copolymers, including diglycollate, that exhibit a high molecular weight could also be obtained from the reaction of 1,2 , and 4 . It was found that the molecular weights of the copolymers decreased as the ratio of 2 increased. The compositions of the copolymers were the same as the feed compositions. The biodegradability of the copolymers rose with an increase in the ratio of 2 .

\section{REFERENCES}

1. S. Takenouchi, A. Takasu, Y. Inai, and T. Hirabayashi, Polym. J., 33, 746 (2001).

2. T. Hayashi, H. Kanai, and T. Hayashi, Polym. J., 33, 38 (2001).

3. J. Li, Y. He, and Y. Inoue, Polym. J., 33, 336 (2001).

4. H. Pranamuda, R. Chollakup, and Y. Tokiwa, Appl. Environ. Microbiol., 65, 4220 (1999).

5. Y. He, T. Masuda, A. Cao, N. Yoshie, Y. Doi, and Y. Inoue,
Polym. J., 31, 184 (1999).

6. H. Pranamuda, Y. Tokiwa, and H. Tanaka, Appl. Environ. Microbiol., 61, 1828 (1995).

7. A. Cao, T. Okamura, C. Ishiguro, K. Nakayama, Y. Inoue, and T. Masuda, Polymer, 43, 671 (2002).

8. Y. Taguchi, A. Oishi, K. Fujita, Y. Ikeda, K. Watanabe, and T. Masuda, J. Oleo Sci., 49, 825 (2000).

9. A. Oishi, H. Nakano, K. Fujita, M. Yuasa, and Y. Taguchi, Polym. J., 34, 742 (2002).

10. M. Zhang, K. Nakayama, Y. Taguchi, A. Oishi, and T. Masuda, presented at the $12^{\text {th }}$ International Symposium on Fine Chemicals and Functional Polymers, Lanzhen, China, 2002.8 .

11. T. Masuda and A. Cao, Jpn. Kokai, 2002-356548 (2002).

12. Y. Maeda, A. Nakayama, T. Takeuchi, M. Ogawa, N. Kawasaki, K. Hayashi, N. Yamamoto, and S. Aiba, Kobunshi Ronbunshu, 55, 145 (1998).

13. Y. Yoo, M. Ko, S. Han, T. Kim, S. Im, and D. Kim, Polym. J., 30, 538 (1998).

14. S. Takenouchi, A. Takasu, Y. Inai, and T. Hirabayashi, Polym. Prepr., Jpn., 49, 1010 (2000).

15. G. Seretoudi, D. Bikiaris, and C. Panayiotou, Polymer, 43, 5405 (2002). 